\title{
Identifying priority areas for ecosystem service management in South African grasslands
}

\author{
Benis N. Egoh ${ }^{\mathrm{a}, \mathrm{b}, *}$, Belinda Reyers ${ }^{\mathrm{a}}$, Mathieu Rouget ${ }^{\mathrm{c}}$, David M. Richardson ${ }^{\mathrm{b}}$ \\ a Natural Resources and the Environment, Council for Scientific and Industrial Research, P.O. Box 320, Stellenbosch 7599, South Africa \\ ${ }^{\mathrm{b}}$ Centre for Invasion Biology, Department of Botany E Zoology, Stellenbosch University, Private Bag X1, Matieland 7602, South Africa \\ ${ }^{\mathrm{c}}$ Department of Plant Science, University of Pretoria, Pretoria 0002, South Africa
}

\section{A R T I C L E I N F O}

\section{Article history:}

Received 12 May 2010

Received in revised form 9 December 2010

Accepted 20 January 2011

Available online $\mathrm{xxx}$

\section{Keywords:}

Ecosystem services

Biodiversity

Systematic conservation planning

Carbon

Water

Soil

\begin{abstract}
A B S T R A C T
Grasslands provide many ecosystem services required to support human well-being and are home to a diverse fauna and flora. Degradation of grasslands due to agriculture and other forms of land use threaten biodiversity and ecosystem services. Various efforts are underway around the world to stem these declines. The Grassland Programme in South Africa is one such initiative and is aimed at safeguarding both biodiversity and ecosystem services. As part of this developing programme, we identified spatial priority areas for ecosystem services, tested the effect of different target levels of ecosystem services used to identify priority areas, and evaluated whether biodiversity priority areas can be aligned with those for ecosystem services. We mapped five ecosystem services (below ground carbon storage, surface water supply, water flow regulation, soil accumulation and soil retention) and identified priority areas for individual ecosystem services and for all five services at the scale of quaternary catchments. Planning for individual ecosystem services showed that, depending on the ecosystem service of interest, between $4 \%$ and $13 \%$ of the grassland biome was required to conserve at least $40 \%$ of the soil and water services. Thirty-four percent of the biome was needed to conserve $40 \%$ of the carbon service in the grassland. Priority areas identified for five ecosystem services under three target levels $(20 \%, 40 \%, 60 \%$ of the total amount) showed that between $17 \%$ and $56 \%$ of the grassland biome was needed to conserve these ecosystem services. There was moderate to high overlap between priority areas selected for ecosystem services and already-identified terrestrial and freshwater biodiversity priority areas. This level of overlap coupled with low irreplaceability values obtained when planning for individual ecosystem services makes it possible to combine biodiversity and ecosystem services in one plan using systematic conservation planning.
\end{abstract}

(c) 2011 Elsevier Ltd. All rights reserved.

\section{Introduction}

Grasslands cover about $40 \%$ of the earth's surface and are found in every continent of the world except Antarctica (White et al., 2000). The grassland biome is home to about one billion people around the world and is the source of many ecosystem services required to support these people and others outside the biome. Ecosystem services are the benefits humans derive from ecosystems and could be direct (e.g. food supply) or indirect (e.g. climate regulation). Many communities around the world graze their animals in the grasslands or hunt wild animals and collect

\footnotetext{
* Corresponding author. Present address: Department of Plant Science, University of Pretoria, Pretoria 0002, South Africa.

E-mail address: ebenis@gmail.com (B.N. Egoh).
}

medicinal plants, fruits, and thatch grass from grasslands (Sala and Paruelo, 1997; Friday et al., 1999; Dzerefos and Witkowski, 2004). In South Africa, approximately $30 \%$ of all plants sold in traditional medicine markets grow in grasslands (Williams et al., 2000). Grasslands also sequester carbon as soil organic matter stored mostly below ground (Burke et al., 1989; Sala and Paruelo, 1997), reducing the amount of carbon in the atmosphere that contributes to climate change. One of the most valuable services provided by grasslands is that of water supply. Grasslands play a crucial role in the hydrological cycle by reducing immediate runoff and erosion, and by storing runoff as groundwater or in wetlands contributing to the service of water supply (Kotze and Morris, 2001). Aside from these ecosystem services, grasslands are also rich in biodiversity. Globally, grasslands house many important species and include $15 \%$ of the world's Centres of Plant Endemism, 11\% of Endemic Bird Areas and $29 \%$ of ecoregions with outstanding biological distinctiveness (White et al., 2000). 
Grasslands are currently being degraded and transformed by agriculture, overgrazing, mining and other forms of extractive land uses. The Millennium Ecosystem Assessment highlighted that temperate grasslands had lost more than $70 \%$ of their natural cover by 1950 (MA, 2005). In South Africa, the grassland biome is the most threatened biome with about 35\% habitat transformation from cultivation, urbanisation, overgrazing and mining (Reyers et al., 2005). Declines in grassland ecosystems and associated biodiversity and ecosystem services demand urgent strategies to improve the condition of grasslands (WRI, 2001; MA, 2005).

In exploring ways to conserve areas like the grasslands to safeguard biodiversity and ecosystem services, several studies have focused on assessing ecosystem service congruence with biodiversity (Chan et al., 2006; Turner et al., 2007; Naidoo et al., 2008; Egoh et al., 2009) without necessarily identifying priority areas for ecosystem services. As highlighted in Egoh et al. (2007, 2010) and demonstrated by Chan et al. (2006), planning for ecosystem services can benefit from the two decades of research and development that has gone into the field of conservation planning, a subdiscipline of conservation biology which deals with identifying spatial priorities for conservation actions. Systematic conservation planning (SCP) has already been used extensively around the world to plan for biodiversity (Margules and Pressey, 2000; Sarkar et al., 2006).

The South African Grasslands Programme (a biome-wide conservation programme for the grasslands of South Africa; http:// www.grasslands.org.za) is one of many programmes around the world aimed at reducing declines in biodiversity and ecosystem services in grasslands. The main objective of the programme is to integrate biodiversity conservation into production sectors (e.g. agriculture, mining and forest plantations) to bridge the gap between science, policy and implementation. Most of these sectors rely on ecosystem services (e.g. water supply) produced in the grassland biome. The role of the grasslands in supporting human well-being makes it crucial for ecosystem services to be considered by the programme. The programme has taken a broad approach to conservation in targeting both biodiversity and ecosystem services in its efforts to mainstream biodiversity into other sectors involved in grassland management and use. The programme began with a systematic conservation plan in order to focus its efforts spatially. In this plan the programme opted to combine biodiversity and ecosystem services. This study reports on the systematic conservation plan initiated as part of the Grasslands programme. At the time of this study (2004), it was quite visionary for an implementation programme such as this one to identify ecosystem service priority areas.

This study examined ways to identify priority areas for ecosystem services and how such priorities could be aligned with existing biodiversity priority areas. Our specific objectives were to a) identify areas where conservation efforts should be directed for individual ecosystem services and for bundles of ecosystem services in the grassland biome; b) test the effect of different target levels of ecosystem services used to identify priority areas; and c) evaluate the extent to which biodiversity and ecosystem services priorities overlap. The study used existing terrestrial and freshwater biodiversity priority areas identified for South Africa (Nel et al., 2007; Reyers et al., 2007).

\section{Methods}

\subsection{Study area}

The South African grassland biome as defined by Mucina and Rutherford (2006) covers an area of about $339240 \mathrm{~km}^{2}$ (373 $990 \mathrm{~km}^{2}$ including Lesotho and Swaziland) and contains 73 vegetation types. The biome overlaps with several of South Africa's provinces (Fig. 1). Annual rainfall in southern African grasslands ranges from 400 to $>1200 \mathrm{~mm} \mathrm{yr}^{-1}$; altitude ranges from sea level to $>3300 \mathrm{~m}$ and soil types range from humic-clay to poorly structured sands (O'Connor and Bredenkamp, 1997). South African grasslands host a very high diversity and endemism of plant and animal species. Thirty-eight river ecosystems have also been

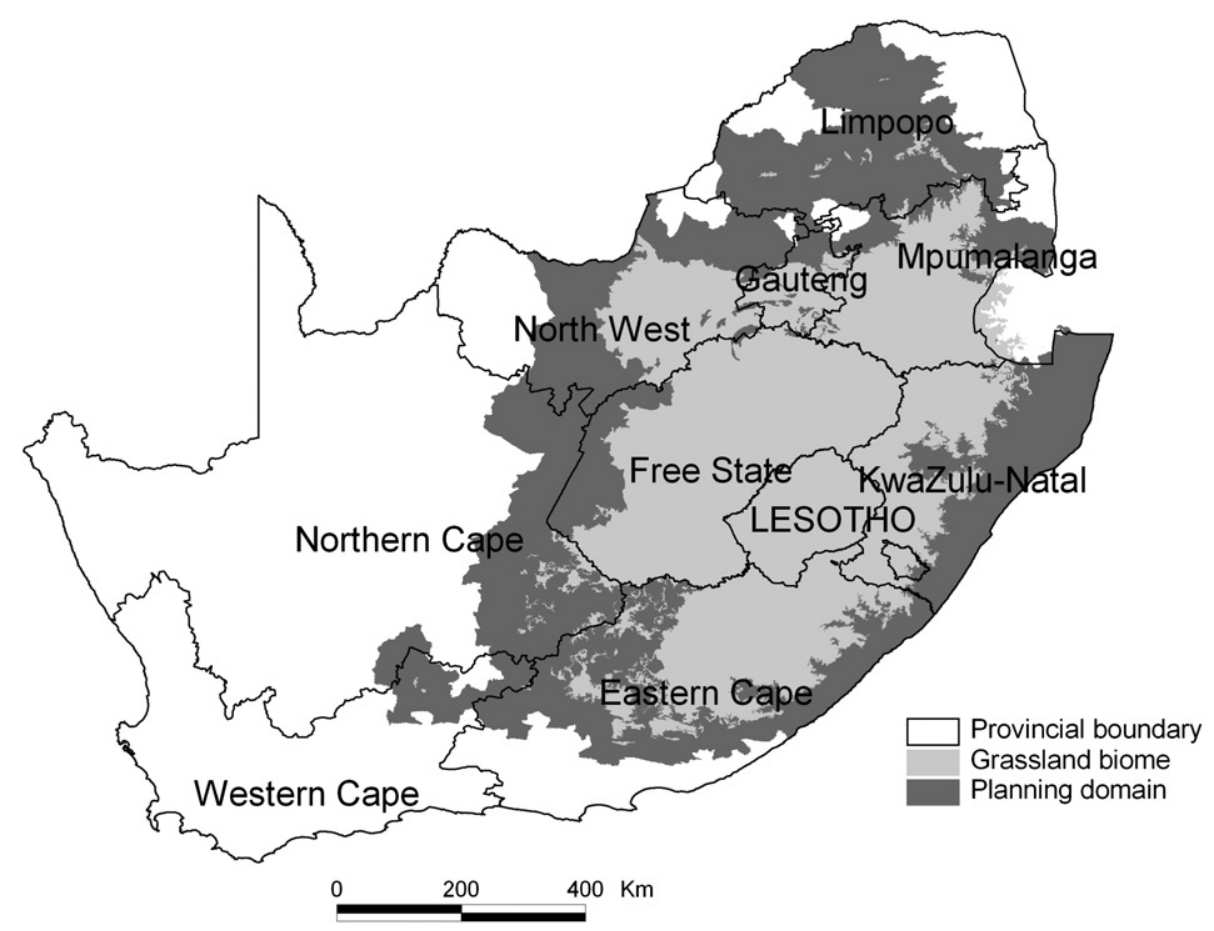

Fig. 1. The grassland biome of South Africa (according to Mucina and Rutherford, 2006), showing provincial boundaries. 
identified within the grasslands in South Africa as critical for conserving freshwater ecosystems (Nel et al., 2007). The grasslands are the most productive biome in terms of agriculture in South Africa (Mentis and Huntley, 1982). Agricultural practices impact negatively on both biodiversity and ecosystem services. In South Africa, irrigated agriculture takes place on 1.3 million hectares of land (almost $10 \%$ of the total cultivated area) and uses an estimated 12.3 billion cubic metres of surface and groundwater per year, which constitute $56 \%$ of the country's total annual water use (WRC, 2000). Water supply services are also highly threatened by invasive alien plants which consume more water than native vegetation (Van Wilgen et al., 2008). The high dependence of food supply on water services, coupled with the high threat facing water supply, makes water a crucial ecosystem service in South Africa.

\subsection{Data}

\subsubsection{Ecosystem services}

Five ecosystem services were selected for this study based on their importance in the grassland biome, the availability of data, and the extent to which they rely on natural vegetation cover. The services include water supply and regulation, soil retention and accumulation, and carbon storage. Data used for mapping water supply and flow regulation, soil retention and accumulation are described in Egoh et al. (2008). Carbon storage data used in this study were extracted from a global soil dataset (GSDT, 2002).

Although driven by similar ecosystem processes, these services differ in terms of interactions among processes, importance of processes and therefore areas of high ecosystem service provision. For example, high water supply areas are concentrated in the Eastern parts of the grassland biome, whereas areas important for water regulation tend to occur in the central part. This has important implications for spatial planning. Previous studies showed that spatial correlation amongst these five services was low to moderate (Egoh et al., 2008). A brief description of how the services were mapped is given below.

2.2.1.1. Surface water supply. Surface water supply is a function of the quantity and quality of water available for direct use by humans. Egoh et al. (2008) mapped important areas for delivering water supply in South Africa as areas of high runoff. Water quality was not mapped separately as it is strongly correlated with water quantity (runoff). Adequate management of these areas to retain natural vegetation cover will maintain or improve water quality. Indeed, areas of high natural cover yield high quality water, with the lowest possible soil erosion, and nutrient and sediment loss (Scanlon et al., 2007).

2.2.1.2. Water flow regulation. Water flow regulation is the storage component of the water services and is a function of the contribution of groundwater to base flow. Water flow regulation was mapped as the contribution of groundwater to base flow per quaternary catchment for the whole country (DWAF, 2005). Data on water flow regulation for the grassland biome were extracted from this national dataset (also see Egoh et al., 2008). Data were summarised into litres per quaternary catchment.

2.2.1.3. Carbon storage. The retention of carbon stored above or below ground has the potential to mitigate climate change impacts. Data on carbon storage $\left(\mathrm{kg} / \mathrm{m}^{2}\right)$ were extracted from the ISRICWISE Global Dataset of Derived Soil Properties, southern Africa (GSDT, 2002). This dataset contained data on soil-carbon density, total nitrogen density, profile of available water capacity amongst others. Only the carbon storage data were extracted from this dataset and summarised into tons per quaternary catchment. As mentioned above, carbon storage in the grassland occurs mostly below ground and no quantitative data on above-ground biomass were available for the entire study area.

2.2.1.4. Soil retention. Soil retention is the ability of vegetation cover to retain soils in order to prevent erosion. Natural vegetation cover needs to be maintained in areas with high erodibility to ensure the continuous delivery of the services of land productivity and to prevent erosion and its consequences such as sedimentation and eutrophication of nearby rivers. Soil retention is an important service in the grasslands where cultivation and grazing are major land uses. Soil retention was mapped as a function of vegetation cover and soil erosion potential (Egoh et al., 2008). The service of soil retention is localised and the hotspots are most vulnerable. Therefore only the soil retention hotspots for the grassland were considered in this study and extracted from the national dataset and summarised in ha of soil retention hotspot per quaternary catchment.

2.2.1.5. Soil accumulation. The accumulation of soil organic matter is an important process of soil formation which can be negatively affected by habitat degradation and transformation (de Groot et al., 2002). Egoh et al. (2008) mapped soil accumulation as a function of soil depth and litter accumulation for the whole country using data from Schoeman et al. (2002) and Schulze (2004) respectively. Such areas, especially the hotspots are key nutrient sinks and needs to be kept in natural condition. Hotspots of soil accumulation were extracted from Egoh et al. (2008) for this study and summarised per quaternary catchment.

\subsubsection{Biodiversity priority areas}

2.2.2.1. Terrestrial biodiversity priority areas. Biodiversity is defined as genes, species, ecosystems and the processes that sustain them (Noss, 1990). Although biodiversity underpins most ecosystem services, in most cases it is only specific components of biodiversity (e.g. medicinal plants, wetlands) that provide direct benefits to humans. Two previous studies identified terrestrial and freshwater biodiversity priority areas at a national scale based on the most comprehensive datasets available, without explicitly including ecosystem services. Reyers et al. (2007) developed species and habitat scores as part of the 2005 National Spatial Biodiversity Assessment (NSBA) for South Africa. Species scores were derived for each quarter-degree cell (an area of $\sim 700 \mathrm{~km}^{2}$ ) based on irreplaceability patterns for 10000 endemic and 1500 threatened plants and animal species, respectively. Habitat scores were derived based on irreplaceability, conservation status and protection level of 430 vegetation types. Reyers et al. (2005) also updated the existing overall biodiversity priority areas using an updated landcover dataset for the Grassland biome. We used the species and habitat scores (ranging from 0 to 100), as an input layer when planning for ecosystem services in scenario 4 below. The refined overall terrestrial biodiversity priority map (from Reyers et al., 2005) was used to evaluate overlap between biodiversity priorities and ecosystem service priorities.

2.2.2.2. Freshwater biodiversity priority data. Data on freshwater biodiversity priority areas consisted of an assessment of the condition and status of river types which Nel et al. (2007) used to identify threatened river types. Freshwater priority areas were defined as intact tributaries of critically endangered river types within the grassland biomes (see Reyers et al., 2005). Quaternary catchments containing any of the selected tributaries were assigned a score of 100 , while all other catchments were given a score of 0 . We assigned the score of 100 because these were rivers already selected as national priority areas which must be included 
in any conservation action strategy. This dataset was used as freshwater biodiversity priority map when planning for ecosystem services and assessing overlaps (see below, scenario 4).

\subsection{Analysis}

\subsubsection{Planning unit and data preparation}

South African water resources are managed in catchments (watersheds) ranging from primary to quaternary catchments. A catchment is defined as the area of land that is drained by a single river system, including its tributaries (DWAF, 2004). Quaternary water catchments were chosen as planning units for this study because most of the data we obtained were at this resolution. In South Africa quaternary catchments are about 400-600 000 ha in size, with a mean of about 57000 ha. All water catchments with at least $10 \%$ of their area covered by grassland were selected as part of the planning domain. This resulted in 1190 catchments - a larger area than the Grassland biome. All ecosystem services data, biodiversity scores for species, terrestrial habitat and freshwater priority areas were summarised per quaternary catchment.

\subsubsection{Identifying ecosystem service and biodiversity priorities within the grassland biome}

We identified priorities for a) individual ecosystem services, b) bundles of ecosystem services (scenario 1-3 below), and c) ecosystem services plus biodiversity (scenario 4). The goal of conservation plans is to select geographic areas which achieve certain biodiversity or ecosystem service targets while minimising costs (often associated with the size of the planning units). Here we identified sets of quaternary catchment to achieve targets for ecosystem services while minimising the total area of quaternary catchments selected. We used simulated annealing within MARXAN version 1.8.2 (1000 runs and 1000000 iterations) for all analyses (Possingham et al., 2000). We set targets and planned for individual ecosystem services, and then tested a range of targets while planning for all five services together. Finally, we integrated biodiversity and ecosystem services into one plan.

Determining quantitative targets for ecosystem service planning continues to be a challenge and is a significant obstacle in adapting algorithms such as MARXAN for planning based on ecosystem service features (Carwardine et al., 2009). Biodiversity targets can be based on ecological knowledge and thresholds (e.g. species-area curves, or population viability analyses) or social or political values (e.g. IUCN's 10\% recommendation for protected area extent). Targets for ecosystem services could be based on biophysical thresholds or societal need or goals. Some examples include the natural area needed for pollination, the area of a watershed needed for water purification, and the amount of clean water needed by a village per year. van Jaarsveld et al. (2005) used current demand as a way of setting ecosystem service targets, but this approach ignores future demands, and ecological thresholds and needs for these services (e.g. the "ecological reserve" in a river). Generally, this level of information is lacking and sets major challenges for planning for ecosystem services. We used arbitrary targets (40\% of total water and carbon produced, $50 \%$ of the total area for hotspots of soil services) when planning for individual ecosystem services and explored a range of targets for bundles of ecosystem services (see scenario 1-3 below) in order to explore the effect of target uncertainty on outcomes.

2.3.2.1. Scenario 1. As mentioned above, targets for ecosystem services are not yet clear, so we tested different targets levels in prioritising ecosystem services. In this scenario we set a $20 \%$ target for three of the five services, doubling the IUCN $10 \%$ required for biodiversity (Table 1 ). The target of $20 \%$ of total supply of services
Table 1

Input data for four scenarios used to identify priorities for ecosystem services. One of the scenarios includes biodiversity priorities as input layers.

\begin{tabular}{|c|c|c|c|c|}
\hline \multirow[t]{2}{*}{ Ecosystem services } & \multicolumn{4}{|l|}{ Target } \\
\hline & Scenario 1 & Scenario 2 & Scenario 3 & Scenario 4 \\
\hline Water supply & $20 \%$ & $40 \%$ & $60 \%$ & $40 \%$ \\
\hline $\begin{array}{l}\text { Water flow } \\
\text { regulation }\end{array}$ & $20 \%$ & $40 \%$ & $60 \%$ & $40 \%$ \\
\hline Carbon & $20 \%$ & $40 \%$ & $60 \%$ & $40 \%$ \\
\hline Soil retention & $50 \%$ & $50 \%$ & $50 \%$ & $50 \%$ \\
\hline Soil accumulation & $50 \%$ & $50 \%$ & $50 \%$ & $50 \%$ \\
\hline $\begin{array}{l}\text { Terrestrial } \\
\text { biodiversity }\end{array}$ & - & - & - & $\begin{array}{l}\text { Prioritised through } \\
\text { lowering cost) }\end{array}$ \\
\hline $\begin{array}{l}\text { Freshwater } \\
\text { biodiversity }\end{array}$ & - & - & - & $\begin{array}{l}\text { Prioritised through } \\
\text { lowering cost) }\end{array}$ \\
\hline
\end{tabular}

was used for surface water supply, water flow regulation, and carbon storage. The benefits from the services of soil retention and accumulation are more local (unlike water which can be transferred from one area to people in other regions or carbon which has global benefits) and needs the entire hotspot to be kept in good condition. However, a 100\% target seemed unfeasible and therefore we chose a $50 \%$ target of each hotspot. In order to minimise the total area selected in each reserve network, we used catchment area as a cost layer to bias selection to favour smaller catchments in this scenario and all others.

2.3.2.2. Scenario 2. In this scenario, we increased the target levels for surface water supply, water flow regulation and carbon storage from $20 \%$ to $40 \%$ but maintained the $50 \%$ targets for soil services. To achieve these targets, MARXAN selects the minimum number of catchments that delivers $40 \%$ of the total water available in the study area, $40 \%$ of the total carbon stored and $50 \%$ of the total area providing soil services.

2.3.2.3. Scenario 3. We increased the target level for surface water supply, water flow regulation, and carbon to $60 \%$ in this scenario. However, we maintained the targets for soil services in order to compare results with those from scenarios 1 and 2 . Targets set for soil retention and accumulation remained at $50 \%$ of hotspots.

2.3.2.4. Scenario 4 (integrated assessment). The aim of this scenario was to align biodiversity priorities with those of ecosystem services in planning. We did this by aiming to achieve targets for ecosystem services in biodiversity priority areas where possible. We used terrestrial (species and habitat) and freshwater priorities as input layers and maintained the ecosystem services targets from scenario 2. To ensure that planning units with higher biodiversity values were more likely to be selected, we summed the priority scores for species $(0-100)$, habitat $(0-100)$ and freshwater biodiversity (100). The scores were combined and rescaled between 0 and 100 , and planning units with a species/ habitat/freshwater biodiversity score of 0 were assigned the maximum cost value (100) and planning units with a species/ habitat/freshwater score of 100 , the lowest cost value (0). In this way, catchments important for biodiversity would receive a very low cost and were more likely to be selected.

Results from all scenarios were summarised using the best solution (the reserve network that selects the best set of sites that meets targets at minimum cost). Proportional overlap (measured as the area shared between two priorities as a percentage of the area of the priority map with a smaller total area) was used to calculate overlap between ecosystems service priorities (best solution) from Scenarios 1-4 and freshwater and terrestrial biodiversity priorities from the 2005 NSBA. Results were summarised both in terms of percentage of water catchments and percentage of the Grassland 
biome. We also assessed the frequency with which catchments were selected from the 1000 runs per scenario. This frequency of selection serves as an estimate of irreplaceability defined as the likelihood that a given site is needed to achieve a specified set of conservation targets (Ferrier et al., 2000). Planning units with high frequency values were selected more often or were more important in meeting specified targets. We calculated this frequency by dividing the number of times a catchment is selected by the number of runs. We estimated the percentage of catchments selected for four frequency classes $(0-0.25,>0.25-0.5,>0.5-0.75$, $>0.75$ ) for each scenario.

\section{Results}

\subsection{Identifying ecosystem service priorities within the grassland} biome

In the first set of analyses, planning for individual ecosystem services showed that between $4 \%$ and $13 \%$ of the grassland biome was required to conserve at least $40 \%$ of water services and $50 \%$ of the soil services in the grassland. When planning for carbon only, $34 \%$ of the biome was needed to produce $40 \%$ of the total carbon. In the second set of analyses, planning for all services in scenario 1 showed that only $17 \%$ of the grassland biome was required to produce $20 \%$ of the water and carbon services plus $50 \%$ of soil services. The area selected for conservation interventions to enhance delivery of ecosystem services when planning for ecosystem services did not necessarily increase with an increase in the number of ecosystem services. For example, meeting targets for scenario 2 showed that only $35 \%$ of the study area was needed. This number is not far from the $34 \%$ reported for carbon storage alone. As expected, the percentage area of the grassland selected to conserve all five services increased with an increase in target. In scenario $3,56 \%$ of the study area was needed to produce $60 \%$ of all water and carbon services and $50 \%$ of the soil services. In Scenario 2 and 3, the best set of catchments selected to meet ecosystem services targets were scattered across the study area (Fig. 2a-c). This pattern differed from previously identified terrestrial and freshwater biodiversity priority areas which formed clusters in different parts of the study area (Fig. 2d and e). a

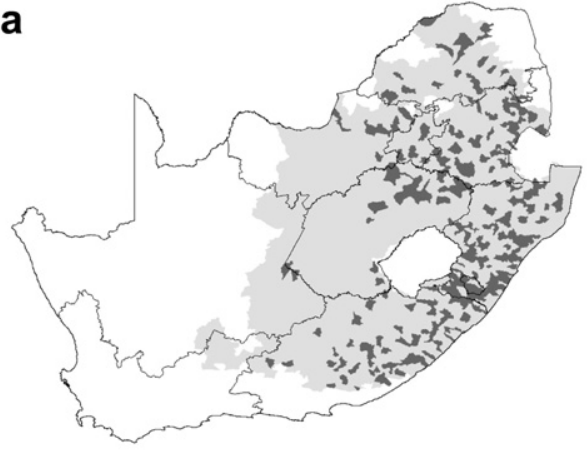

c
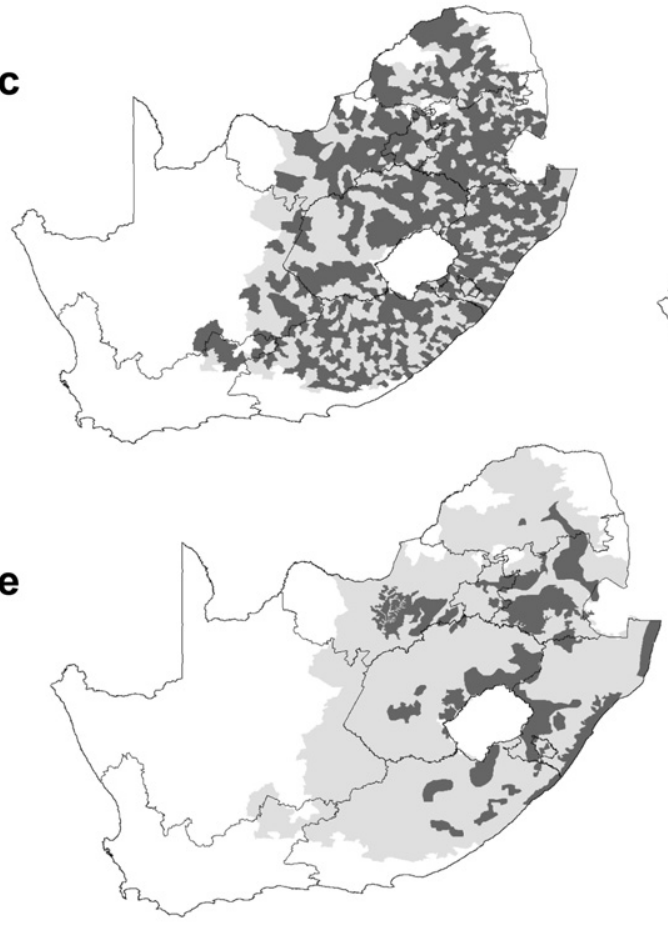

$0 \quad 200400 \mathrm{Km}$
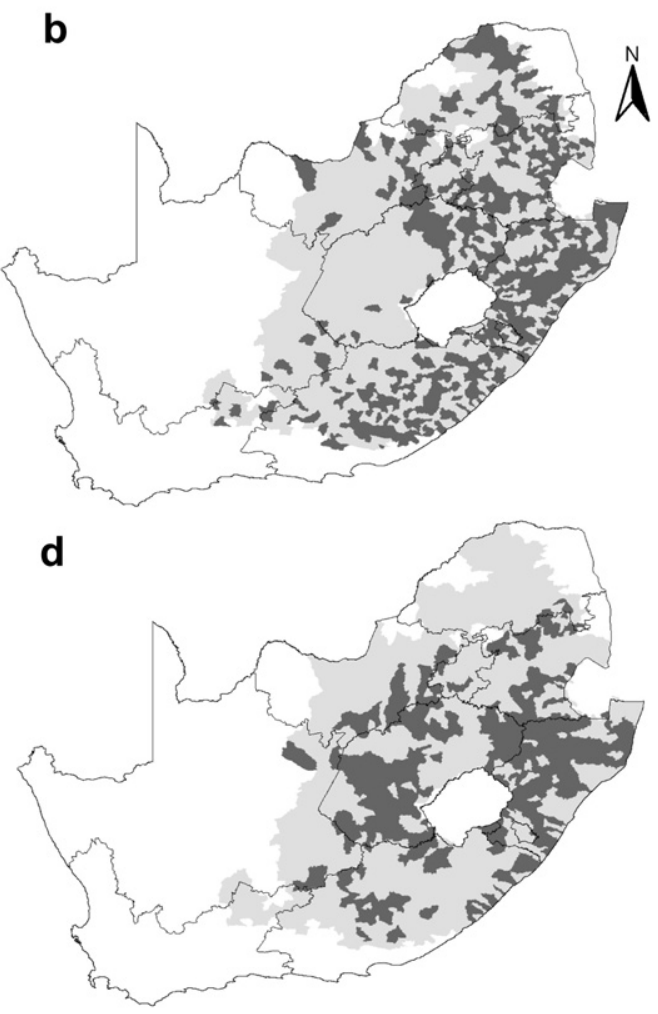

Provincial boundary

Priority sites

Planing domain

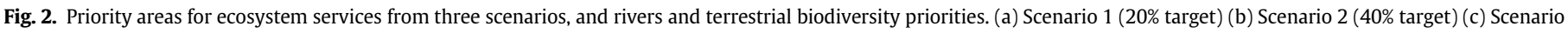
3 (60\% target) (d) Freshwater biodiversity priorities (e) Terrestrial priorities. 


\subsection{Aligning ecosystem service priority areas with biodiversity priority areas}

Focussing conservation on areas that are important for provision of various ecosystem services might benefit biodiversity and vice versa, especially if similar management regimes are required. At least this was the case as shown by results from Scenario 4 and overlap between Scenario 2 and biodiversity priority area. The percentage area of the grassland selected to meet targets for both ecosystem services and biodiversity priorities in Scenario 4 was only slightly higher (40\%) than that for Scenario 2 (35\%) where biodiversity was not considered in the plan. About $40 \%$ overlap was observed between priorities selected for Scenario 2 with both freshwater and terrestrial biodiversity priorities (Table 2). An $86 \%$ overlap was observed between the integrated plan and freshwater priorities and $47 \%$ overlap with terrestrial priorities.

\subsection{Frequency of selection when planning for ecosystem services and aligned with biodiversity priorities}

The degree of flexibility when planning for individual ecosystem services differed between ecosystem services as reflected in patterns of selection of planning units. Planning for water services showed that $19 \%$ of catchments had frequency values $>0.5$ for surface water supply and $7 \%$ for water flow regulation. This implies that only a few irreplaceable catchments contribute the most in water supply and regulation services as demonstrated by the fact that areas with frequency of $>0.5$ covered only $9 \%$ of the grassland biome for water supply and 3\% for water flow regulation. The service of carbon sequestration was distributed throughout the study area and was seen in the results where $30 \%$ of the catchments ( $25 \%$ of the grassland) had frequency values $>0.5$ when planning for carbon storage alone. However, there were few clusters in the forest vegetation. Soil services were also distributed across the study area with different sections of catchments contributing to this service. Frequency maps of soil accumulation and soil retention showed that $15 \%$ ( $12 \%$ of the grassland biome) and $19 \%$ ( $11 \%$ of the grassland biome) of catchments respectively had values $>0.5$. These catchments were found in different parts of eastern seaboard for both services and a few in far north for soil accumulation.

Planning for all five services at once showed that few catchments contributed significantly to all five services which were highly irreplaceable. Results from Scenario 1 showed that $8 \%$ (4\% of grassland biome) of all catchments had frequencies $>0.5$. However, the flexibility of catchments selected to meet target for ecosystem services reduced as the target levels increased (Fig. 3). This is expected because high targets indicate that more catchments are ultimately needed to meet those targets. In Scenario 2, 33\% (28\% of the grassland biome) of the catchments had a frequency value of $>0.5$. Similarly, Scenario 3 results showed that a larger number of catchments $(>90 \%$ ) had frequency values $>0.5$, but few catchments $(<2 \%)$ had a value $>0.75$. When biodiversity was introduced in Scenario 4 as a cost layer, more catchments became either highly irreplaceable with frequency values $>0.75$ or not needed with

Table 2

Proportional overlap between ecosystem services and biodiversity priorities. Overlap is based on area rather than number of catchments.

\begin{tabular}{lll}
\hline \multirow{2}{*}{ Ecosystem service priorities } & \multicolumn{2}{l}{ Biodiversity priority } \\
\cline { 2 - 3 } & Freshwater & Terrestrial \\
\hline Scenario 1 (20\% target) & $34 \%$ & $39 \%$ \\
Scenario 2 (40\% target) & $39 \%$ & $41 \%$ \\
Scenario 3 (60\% target) & $60 \%$ & $60 \%$ \\
Scenario 4 (Integrated plan) & $86 \%$ & $47 \%$ \\
\hline
\end{tabular}

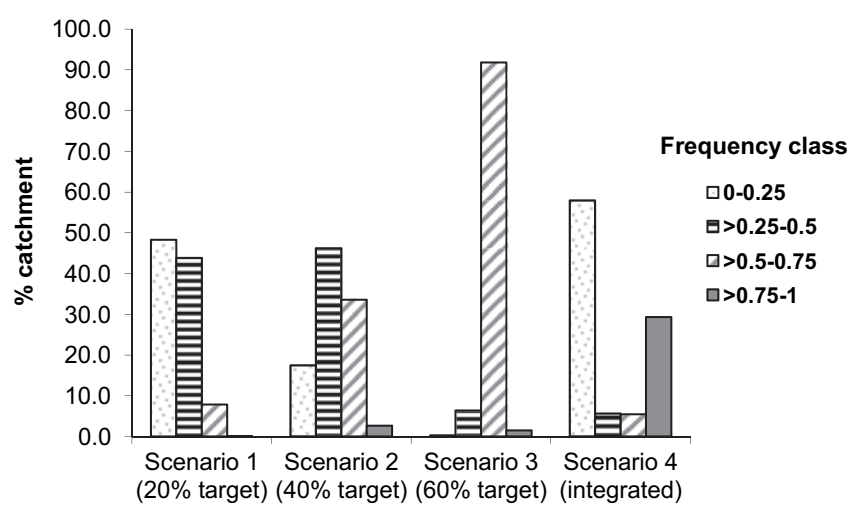

Fig. 3. Percentage of catchments selected for each category of irreplaceability values.

values $\leq 0.25$. The results from Scenario 4 (integrated plan) showed fewer catchments $(<10 \%)$ with frequency ranging from $>0.5-0.75$. Most of the highly irreplaceable catchments were located in KwaZulu-Natal, the Free State and North West provinces (Fig. 4).

\section{Discussion}

This study set out to address the challenge of identifying priority areas for ecosystem services in South Africa's grassland biome exploring the effect of various targets and ways to integrate biodiversity into such priorities. Results suggest that if the right catchments are targeted, only a small area of the biome is needed to produce $40 \%$ of the total water supply. This result is explained by Egoh et al. (2008) where catchments within the range and hotspots of water services form clusters. Conservation intervention geared toward water delivery should ideally be less challenging if the total area selected for intervention is small and if they are in the same place. The costs of acquiring and managing such land and consequently the success of any implementation programme depend partly on these two factors. Larger areas were selected for carbon posing a more challenging intervention. In the case of soil services, small areas were selected, but the selected areas were found scattered throughout the study site. However, clustering could be initiated in software such as Marxan using the boundary length modifier function (an approach that we did not employ due to the focus of this study on target effects). Planning for individual services gives the opportunity of using conservation interventions specific to a particular service. However, a plan considering all services will minimise the area requiring intervention for multiple benefits, as long as similar management interventions (e.g. conservation tillage, vegetation conservation and restoration) are required. This was seen in Scenario 2 where $35 \%$ of the study area was needed to produce at least $40 \%$ of all five services compared to the $34 \%$ for carbon alone.

Another objective of this study was to align ecosystem service priority areas with those for biodiversity. About $40 \%$ of the biome was selected to meet targets for ecosystem services while giving priority to catchments that had already been prioritised for biodiversity conservation. The moderate to high levels of overlap between biodiversity priorities and ecosystem services is consistent with previous findings in South Africa and elsewhere in the world (Chan et al., 2006; Turner et al., 2007; Naidoo et al., 2008; Anderson et al., 2009; Egoh et al., 2009). This is indicative of the close relationship between these services and underlying biodiversity patterns and processes. The best solution in the integrated plan (Scenario 4) mirrored the freshwater biodiversity priorities. However, these results should be interpreted with caution because 


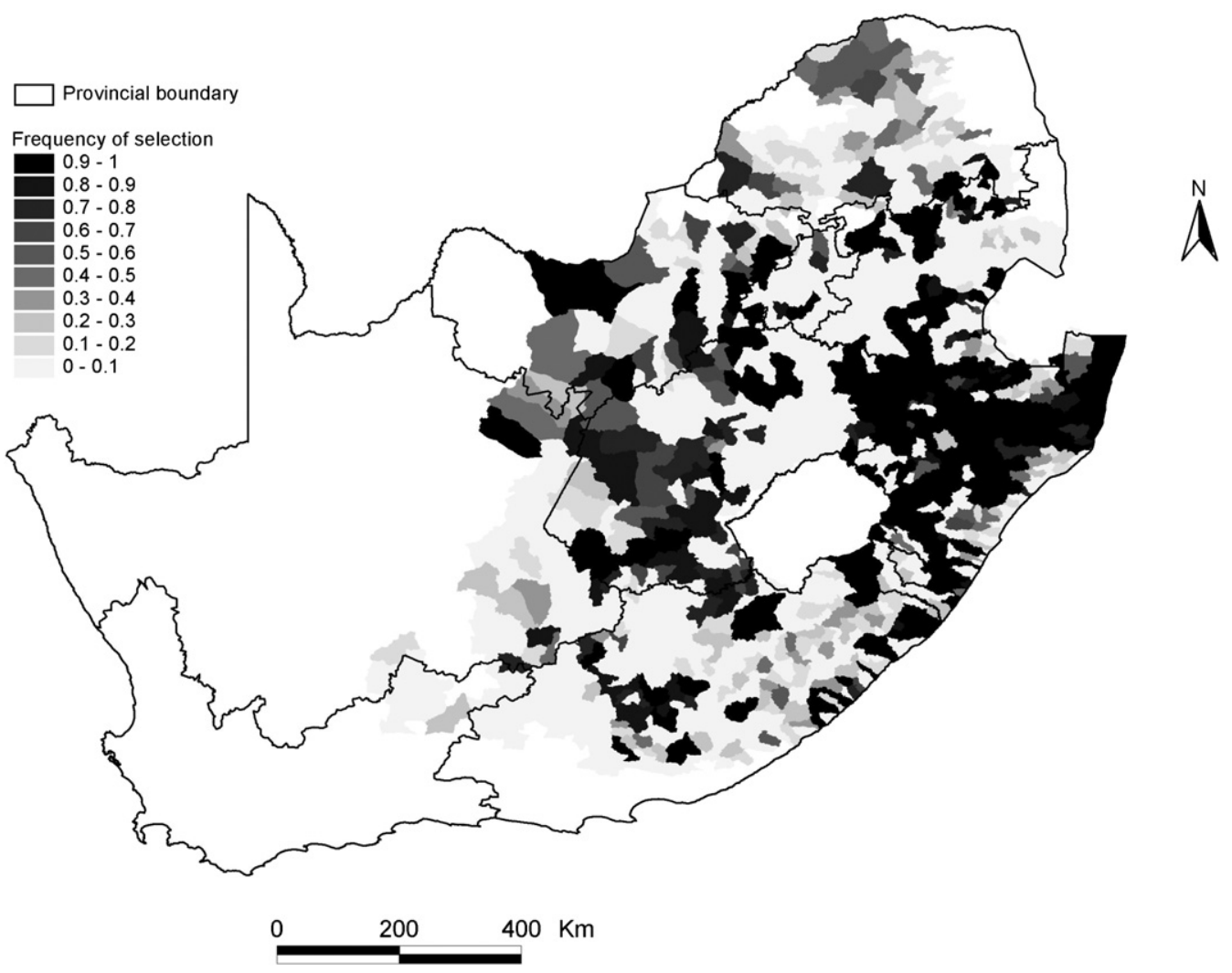

Fig. 4. Importance of catchments in meeting targets for biodiversity and ecosystem services (Scenario 4).

of how the cost layer was derived. While the scores for habitat and species varied from $0-100$, those for the freshwater priorities were the same (100) making catchments selected as a freshwater priority more important in the analysis.

Most studies that have reported moderate to high overlap between biodiversity and ecosystem services such as this one, have mostly considered a few services. Chan et al. (2006) also reported a generally positive, but weak, correlation between the two. A full range of services needs to be investigated with many biodiversity features to make robust conclusions. Naidoo et al. (2008) concluded that conservation priorities aimed solely at biodiversity may not conserve optimal levels of ecosystem services, and vice versa, and that concordance between the two cannot be assumed. Nonetheless, the moderate levels of overlap found in this study and in Egoh et al. (2009) coupled with findings from studies elsewhere in the world (Turner et al., 2007) show that there are benefits in combining some ecosystem services and biodiversity in one spatial plan. In this study frequency patterns for single services revealed that it is spatially possible to integrate ecosystem services and biodiversity in one plan. Only a few catchments were irreplaceable for both water and soil services. The high flexibility shown at lower target levels for ecosystem service, suggests that highly constrained biodiversity features (e.g. endemic species) could be met first before ecosystem services are added.

Few studies have integrated biodiversity and ecosystem services planning as was done in this study. Approaching conservation from the perspective of ecosystem services increases the potential for securing funding and boosting implementation (Pagiola et al., 2010). Funds for conservation can be generated through payments for ecosystem service (PES) programmes (Naidoo and Ricketts, 2006; Turner et al., 2007). Carbon can be sold in a carbon market (although appropriate institutions need to be established) to generate income for conservation. PES programmes are beginning to gain momentum in South Africa, with water and carbon services having the most potential as tradable commodities (Blignaut et al., 2008; Turpie et al., 2008). However, there are concerns that approaching conservation from the perspective of ecosystem services may not favour biodiversity. According to McCauley (2006), making ecosystem services the foundation of our conservation strategy implies that nature is only worth conserving when it provides benefits and is put at risk when such benefits cease to exist. But from our work here it is clear that with careful selection of ecosystem services, targets and approach, the benefits of combining the two objectives can outweigh the cost. Concerns about the mismatch of intrinsic and utilitarian values still require careful thought.

Planning that combines biodiversity and ecosystem services spatially is possible, but the implementation of such plans may be challenging because interventions suitable for biodiversity may not necessarily improve yield in ecosystem services or vice versa. For example, Nelson et al. (2008) showed that policies geared towards maximising for forest cover for carbon only benefit a few species in their study area. Many different interventions are employed for managing different aspects of biodiversity (e.g. no-take reserves and buffer zones and conservancies; Tscharntke et al., 2005; Jones, 2006) resulting in different outcomes. There are also many interventions for ecosystem services and range from restoration programmes based on tree planting for carbon storage to landscape scale change in land use for soil erosion control and water purification. Innovative approaches are needed to combine goals of biodiversity conservation and the sustainable delivery of ecosystem services in a framework of strategy development and implementation. An integrated implementation plan should include a dynamic approach that takes into consideration the different types of possible interventions and associated synergies or tradeoffs between biodiversity and ecosystem services (see Daily et al., 
2009). We used a static approach in this study to identify priority areas for ecosystem services and integrate them with biodiversity priorities. The long-term objective of the Grasslands programme is to ensure that production and development activities are appropriately located and managed, so that biodiversity conservation and the delivery of ecosystem services is not impaired. Therefore implementation is focused on a stewardship approach that involves payments for ecosystem services in identified biodiversity and ecosystem service priority areas to encourage sustainable land use practices in the identified priorities.

\section{Conclusions}

Grasslands in South Africa are both rich in biodiversity and important for providing a variety of ecosystem services. There is an emerging interest in conservation concerns for the grasslands both in South Africa and globally (Reyers et al., 2005). Initiatives such as the Grasslands Programme present an opportunity to conserve both biodiversity and ecosystem services in the biome. Inclusion of ecosystem services in the Grasslands programme, as well as its focus on mainstreaming biodiversity into the production sectors of the grasslands, is a new and promising focus for conservation in the country. The Grasslands programme has achieved remarkable success in engaging with stakeholders from government, private sector and civil society (http://www.grasslands.org.za). This success can partially be attributed to the inclusion of ecosystem services in conservation debates because stakeholders can easily understand the benefits of sustainable land use. In the absence of appropriate planning tools for ecosystem services, systematic conservation planning principles could be used to plan for both ecosystem services and biodiversity (although setting targets for ecosystem services as well as biodiversity remains a challenge). There may be benefits in planning for both ecosystem services and biodiversity using these tools. However, caution must be exercised as delivering ecosystem services and conserving biodiversity may require different implementation strategies and arrangements.

\section{Acknowledgements}

This work was supported by the International Foundation for Science, Stockholm, Sweden through a Grant to BNE, National Research Foundation (NRF) through the DST-NRF Centre of Excellence for Invasion Biology (CIB) at Stellenbosch University, the Council for Scientific and Industrial Research (CSIR), the South African National Biodiversity Institute (SANBI), and the Grasslands programme.

\section{References}

Anderson, B.J., Armsworth, P.R., Eigenbrod, F., Thomas, C.D., Gillings, S. Heinemeyer, A., Roy, D.B., Gaston, K.J., 2009. Spatial covariance between biodiversity and other ecosystem service priorities. Journal of Applied Ecology $46,888-896$.

Blignaut, J., Aronson, J., Mander, M., Marais, C., 2008. Investing in natural capital and economic development: South Africa's Drakensberg Mountains. Ecological Restoration 26, 143-150.

Burke, I.C., Yonker, C.M., Parton, W.J., Cole, C.V., Flach, K., Schimel, D.S., 1989. Texture, climate and cultivation effects on soil organic matter content in U.S. grassland soils. Soil Science Society of America Journal 53, 800-805.

Carwardine, J., Klein, C.J., Wilson, K.A., Pressey, R.L., Possingham, H.P., 2009. Hitting the target and missing the point: target-based conservation planning in context. Conservation Letters 2, 3-10.

Chan, K.M.A., Shaw, M.R., Cameron, D.R., Underwood, E.C., Daily, G.C., 2006. Conservation planning for ecosystem services. PLoS Biology 4, 2138-2152.

Daily, G.C., Polasky, S., Goldstein, J., Kareiva, P.M., Mooney, H.A., Pejchar, L., Ricketts, T.H., Salzman, J., Shallenberger, R., 2009. Ecosystem services in decision making: time to deliver. Frontiers in Ecology and the Environment 7, 21-28.

de Groot, R., Wilson, M.A., Boumans, R.M., 2002. A typology for the classification, description and valuation of ecosystem functions, goods and services. Ecological Economics 41, 393-408.
DWAF, 2004. South African 1:500 000 River Coverage. Resource Quality Services directorate, Department of Water Affairs and Forestry, Pretoria.

DWAF, 2005. Groundwater Resource Assessment Phase 2. Department of Water Affairs and Forestry, Pretoria.

Dzerefos, C.M., Witkowski, E.T.F., 2004. Density and potential utilisation of medicinal grassland plants from Abe Bailey Nature Reserve, South Africa. Biodiversity and Conservation 10, 875-896.

Egoh, B.N., Reyers, B., Carwardine, J., Bode, M., O' Farrell, P.J., Wilson, K.A. Possingham, H.P., Rouget, M., De Lange, W., Richardson, D.M., Cowling, R.M., 2010. Safeguarding biodiversity and ecosystem services in South Africa's Little Karoo: trade-offs and synergies. Conservation Biology 24, 1021-1030.

Egoh, B., Reyers, B., Rouget, M., Bode, M., Richardson, D.M., 2009. Spatial congruence between biodiversity and ecosystem services in South Africa. Biological Conservation 142, 553-562.

Egoh, B., Reyers, B., Rouget, M., Richardson, D.M., Le Maitre, D.C., van Jaarsveld, A.S., 2008. Mapping ecosystem services for planning and management. Agriculture, Ecosystems and Environment 127, 135-140.

Egoh, B., Rouget, M., Reyers, B., Knight, A.T., Cowling, M.R., van Jaarsveld, A.S., Welz, A., 2007. Integrating ecosystem services into conservation assessments: a review. Ecological Economics 63, 714-721.

Ferrier, S., Pressey, R.L., Barrett, T.W., 2000. A new predictor of the irreplaceability of areas for achieving a conservation goal, its application to real-world planning, and a research agenda for further refinement. Biological Conservation 93, 303-325.

Friday, K.S., Drilling, M.E., Garrity, D., 1999. Imperata Grasslands Rehabilitation Using Agroforestry and Assisted Natural Regeneration. International Centre for Research in Agroforestry, Southeast Asia Regional Research Programme, Bogor, Indonesia, p. 167.

Global Soil Data Task, 2002. SAFARI 2000 Selected Soil Characteristics, 10-km Grid (IGBP-DIS). [SAFARI 2000 Selected Soil Characteristics, 10-km Grid (International Geosphere-Biosphere Programme - Data and Information Services)]. Oak Ridge National Laboratory Distributed Active Archive Center, Oak Ridge, Tennessee, USA. Data set Available from: http://www.daac.ornl.gov.

Jones, P.J.S., 2006. Collective action problems pose by no-take zones. Marine Policy 30, 143-156.

Kotze, D., Morris, C., 2001. Grasslands - A Threatened Life-Support System. SHARENET, Howick.

Margules, C.R., Pressey, R.L., 2000. Systematic conservation planning. Nature 405 , 243-253.

McCauley, D., 2006. Selling out on nature. Nature 443, 26-27.

Mentis, M.T., Huntley, B.J., 1982. A Description of the Grassland Biome Project. South African National Scientific Programmes Report No. 62. CSIR, Pretoria.

Millennium Ecosystem Assessment, 2005. Millennium Ecosystem Assessment Synthesis Report. Island Press, Washington, D.C. http://www.maweb.org/en/ Synthesis.aspx (accessed December 2010).

Mucina, L., Rutherford, M., 2006. The Vegetation of South Africa, Lesotho and Swaziland. Strelitzia 19. South African National Biodiversity Institute, Pretoria.

Naidoo, R., Balmford, A., Costanza, R., Fisher, B., Green, R.E., Lehner, B., Malcolm, T.R. Ricketts, T.H., 2008. Global mapping of ecosystem services and conservation priorities. Proceedings of the National Academy of Sciences of the USA 105, 9495-9500.

Naidoo, R., Ricketts, T.H., 2006. Mapping the economic costs and benefits of conservation. PLoS Biology 4, 2153-2164.

Nel, J.L., Roux, D.J., Maree, G., Kleynhans, C.J., Moolman, J., Reyers, B., Rouget, M., Cowling, R.M., 2007. Rivers in peril inside and outside protected areas: a systematic approach to conservation assessment of river ecosystems. Diversity and Distributions 13, 341-352.

Nelson, E., Polasky, S., Lewis, D., Plantinga, A., Lonsdorf, E., White, D., Bael, D. Lawler, J., 2008. Efficiency of incentives to jointly increase carbon sequestration and species conservation on a landscape. Proceedings of the National Academy of Sciences of the USA 105, 9471-9476.

Noss, R.F., 1990. Indicators for monitoring biodiversity: a hierarchical approach. Conservation Biology 4, 355-364.

O'Connor, T.G., Bredenkamp, G.J., 1997. Grassland. In: Cowling, R.M. Richardson, D.M., Pierce, S.M. (Eds.), Vegetation of Southern Africa. Cambridge University Press, Cambridge, U.K, pp. 215-257.

Pagiola, S., Zhang, W., Colom, A., 2010. Can payments for watershed services help finance biodiversity conservation? A spatial analysis of highland Guatemala. Journal of Natural Resources Policy Research 2, 7-24.

Possingham, H.P., Ball, I., Andelman, S., 2000. Mathematical methods for identifying representative reserve networks. In: Ferson, S., Burgman, M. (Eds.), Quantitative Methods for Conservation Biology. Springer-Verlag, pp. 291-305.

Reyers, B., Rouget, M., Jonas, Z., Cowling, R.M., Driver, A., Maze, K., Desmet, P., 2007. Developing products for conservation decision-making: lessons from a spatial biodiversity assessment for South Africa. Diversity and Distributions 13 608-619.

Reyers, B., Nel, J., Egoh, B., Jonas, Z., Rouget, M., 2005. National Grasslands Biodiversity Program: Grassland Biodiversity Profile and Spatial Biodiversity Priority Assessment CSIR Report Number: ENV-S-C 2005-102.

Sala, O.E., Paruelo, J.M., 1997. Ecosystem services in grasslands. In: Daily, G.C. (Ed.) Nature's Services: Societal Dependence on Natural Ecosystems. Island Press, Washington, DC, pp. 237-252.

Sarkar, S., Pressey, R.L., Faith, D.P., Margules, C.R., Fuller, T., Stoms, D.M., Moffett, A. Wilson, K.A., Williams, K.J., Williams, P.H., Andelman, S., 2006. Biodiversity conservation planning tools: present status and challenges for the future. Annual Review of Environment and Resources 31, 123-159. 
Scanlon, B.R., Jolly, I., Sophocleous, M., Zhang, L., 2007. Global impacts of conversions from natural to agricultural ecosystems on water resources: quantity versus quality. Water Resources Research 43, W03437. doi:10.1029/2006WR005486.

Schoeman, J.L., Van Der Walt, M., Monnik, K.A., Thackrah, J., Malherbe, J., Le Roux, R.E., 2002. Development and Application of a Land Capability Classification System for South Africa. Agricultural Research Council (ARC) Institute for Soil, Climate and Water, Pretoria (GW/A/2000/57).

Schulze, R.E., 2004. Determination of baseline land cover variable for applications in assessing land use impacts on hydrological responses in South Africa. WRC Report Number: 1155/1/04. In: Schulze, R.E., Pike, A. (Eds.), Development and Evaluation of an Installed Hydrological Modelling System. School of Bioresources Engineering and Environmental Hydrology, University of Natal, Pietermaritzburg.

Tscharntke, T., Klein, A.M., Kruess, A., Steffan-Dewenter, I., Thies, C., 2005. Landscape perspectives on agricultural intensification and biodiversity - ecosystem service management. Ecology Letters 8, 857-874.

Turner, W.R., Brandon, K., Brooks, T.M., Costanza, R., da Fonseca, G.A.B., Portela, R 2007. Global conservation of biodiversity and ecosystem services. BioScience 57 $868-873$.

Turpie, J.K., Marais, C., Blignaut, J.N., 2008. The working for water programme: evolution of a payments for ecosystem services mechanism that addresses both poverty and ecosystem service delivery in South Africa. Ecological Economics 65, 788-798.

van Jaarsveld, A.S., Biggs, R., Scholes, R., Bohensky, E., Reyers, B., Lynam, T., Musvoto, C. Fabricius, C., 2005. Measuring conditions and trends in ecosystem services at multiple scales: the Southern African Millennium Ecosystem Assessment (SAfMA) experience. Philosophical Transactions of the Royal Society B 360, 425-441.

Van Wilgen, B.W., Reyers, B., Le Maitre, D.C., Richardson, D.M., Schonegevel, L., 2008. A biome-scale assessment of the impact of invasive alien plants on ecosystem services in South Africa. Journal of Environmental Management 89, 336-349.

Water Research Commission, 2000. Improving Agricultural Water Management WRC Report No. TT 127/00. Water Research Commission, Pretoria.

White, R.P., Murray, S.M., Rohweder, M., 2000. Pilot Analysis of Global Ecosystems: Grassland Ecosystems. World Resources Institute, Washington, DC.

Williams, V.L., Balkwill, K., Witkowski, E.T.F., 2000. Unravelling the commercia market for medicinal plants and plant parts on the Witwatersrand, South Africa. Economic Botany 54, 310-327.

World Resources Institute, 2000-2001. People and Ecosystems: The Fraying Web of Life. World Resources Institute, Washington, DC. 